\title{
UNIÓN DE HECHO Y EL DERECHO DE HERENCIA
}

Benjamín Aguilar Llanos. ${ }^{1}$

\section{RESUMEN}

La ley 30007 del 16 de abril del 2013 promulgada el 17 de abril del 2013, otorga derechos sucesorios entre los concubinos, ley que ha acaparado el interés de la ciudadanía en general, por tratarse de un tema, que afecta a un porcentaje muy alto de población peruana, que han fundado familia, no sobre la base del matrimonio, sino de una comunidad de vida, compartiendo mesa, lecho y techo, asumiendo responsabilidades propias de una familia matrimonial pero que no han formalizado legalmente su unión; ahora bien, la ley 30007 , que en materia sucesoria pone a los concubinos a la par de una pareja matrimonial, no los denomina concubinos, aún cuando en el fondo lo sean, sino que llama unión de hecho a esa relación, pero no cualquier unión de hecho recibe este beneficio, sino sólo aquellas que cumplen los requisitos legales que se encuentran en el artículo 326 del Código Civil, norma que describe estas uniones de hecho; en consecuencia estarán comprendidos en la ley 30007, las uniones de hecho heterosexuales, (esta exigencia es constitucional), con una vida en común continua, permanente, ininterrumpida de 2 o más años, y que no exista impedimento matrimonial entre ellos, debiendo sumarse a estas exigencias, que la unión de hecho esté inscrita en el registro personal, o en su defecto exista reconocimiento judicial.

\section{PALABRAS CLAVES}

Derecho Sucesorio. Unión de hecho. Concubinos. Matrimonio. Familia.

\section{ABSTRACT}

Law 30007 of April 16, 2013 promulgated on April 17, 2013, granted inheritance rights to cohabitants. This law has captured the interest of the general public since it deals with an issue that affects a high percentage of the Peruvian population, who have founded family not on the basis of marriage, but rather by living together, sharing a table, bed, and roof, assuming family responsibilities inherent to a marriage but have not legally formalized their union. This Law 30007 puts succession matters awarded to the couple cohabiting at par with those of married couples. It does no called partners cohabitants, even when they actually are so, but instead calls this union a domestic partnership. Nevertheless, for these domestic partnerships to enjoy this benefit, couples must meet the legal requirements set out in Article 326 of the Civil Code. Consequently, this Act 30007 covers heterosexual domestic partnerships, (this requirement is established in the Constitution) with a common, ongoing, stable life, uninterrupted for 2 or more years, and provided that there is no impediment for them to be married. In addition, the domestic partnership must be registered with the personal record, or otherwise recognized by a court.

\section{KEY WORDS}

Inheritance Rights. Domestic Partnership. Cohabitants. Marriage. Family.

\section{INTRODUCCIÓN}

En el derecho sucesorio, existe una exigencia para aquellos que pretendan concurrir a una sucesión, y así en el caso de los cónyuges, para que uno de ellos, el sobreviviente pueda heredar, debe haber existido el matrimonio cuando ocurre el deceso del causante, es decir cuando se abrió la sucesión, y ello responde a que la herencia entre cónyuges tiene como fuente el matrimonio; ahora bien, en el caso de los miembros de una unión de hecho, también la exigencia está dada, si es que al fallecer uno de los integrantes de la unión de hecho, existió la comunidad de vida, en otras palabras, el sobreviviente estuvo viviendo con el que ahora es el causante. Esta exigencia la con-

1 Abogado Docente. Cursos que dicta: en la Universidad Católica, Derecho de Familia y Sucesiones, y en la Universidad Femenina del Sagrado Corazón, en Maestría, Políticas Públicas de Familia, y en pre grado el curso de Sucesiones. 
signa la ley 30007 cuando señala en su artículo 2 lo siguiente: "Para que la unión de hecho dé lugar a derechos sucesorios, es requisito que reúna las condiciones señaladas en el artículo 326 del Código Civil, y se encuentre vigente al momento del fallecimiento de cualquiera de sus miembros". Este requerimiento tiene que cumplirse, pues de otro modo no operaría el derecho sucesorio, sin embargo, la misma ley suma a esta exigencia, que la unión de hecho esté inscrita en el registro o exista reconocimiento judicial, pero si al ocurrir el deceso, no existiera inscripción registral o reconocimiento judicial, la citada ley en su artículo 3 se encarga de señalarnos lo siguiente “... el integrante sobreviviente puede solicitar el reconocimiento judicial de la unión de hecho, si antes del fallecimiento del causante no se hubiera realizado la inscripción registral...”.

\section{¿ERA NECESARIO LA NORMA SUCESORIA ENTRE LOS INTEGRANTES DE UNA UNIÓN DE HECHO?}

No cabe duda que la familia peruana, no se funda sólo en el matrimonio, aún cuando ello es lo deseable, sino igualmente lo está en uniones de hecho que se comportan como sociedades conyugales pero que no tienen respaldo matrimonial. Estas familias, cada vez más van creciendo, y pronto según últimos datos estadísticos como el que aparece en el Decreto Supremo 005-Mindes referido al Plan Nacional de Apoyo a la Familia, nos trae una cifra de $25.7 \%$ de familias que se declaran concubinarias, sin embargo, como sabemos y constatamos en la realidad, esa cifra puede y de hecho es mayor. Hasta antes de la ley, estas uniones de hecho sólo tenían reconocimiento constitucional, para equiparar la sociedad de bienes que se genera dentro de esta unión de hecho, con las normas de la sociedad de gananciales que nace a propósito de un matrimonio, equiparidad que les permite dividir los bienes comunes en partes iguales cuando fenece la unión de hecho, sin embargo nuestra legislación no contemplaba otros derechos a favor de la unión de hecho o concubinato regular y menos el de la herencia, tema que fue materia de discusión por mucho tiempo, sobre todo porque es público y notorio que estas familias no formalizadas legalmente, cumplen todos los deberes que se dan dentro del matrimonio como la comunidad de vida, la cohabitación, la asistencia entre ellos, no hay intereses contrapuestos, sino todo lo contrario, pues ambos se identifican y componen una estructura familiar sólida; son estas razones las que han llevado al legislador a promulgar la ley 30007, empero no será extraño que comience a criticarse la norma, en tanto que en lo que se refiere a herencia y al régimen social de sus bienes, es idéntico al matrimonio, entonces no faltarán quienes terminen preguntándose si esta equiparidad de derechos de los concubinos con los cónyuges, va a terminar desincentivando, desmotivando a las parejas a celebrar matrimonio, en tanto que los mismos derechos de los cónyuges lo tendrían los concubinos, -y en parte pueden tener razón-, pero pierden de vista, que el matrimonio es una institución natural, necesaria e importante dentro de toda sociedad y así lo reconocen los diversos instrumentos legales nacionales e internacionales, como la Constitución Peruana, cuando en su artículo 4, impone al Estado la obligación de promover el matrimonio. Por otro lado, convenciones como la Declaración Universal de Derechos Humanos, el Pacto Internacional de Derechos Civiles y Políticos reconocen al matrimonio como una institución natural por la que se funda familia. No se puede dudar que es en el matrimonio, en donde la procreación de los hijos viene respaldada por una serie de garantías en cuanto a la filiación, que no tienen los nacidos de una unión de hecho, sumado a ello tenemos razones de índole moral y religioso que sustentan la institución matrimonial como necesaria e indispensable en toda sociedad, además de reconocer que siempre ha existido y ha sido fuente estable y segura de fundar familia. No puede igualmente ignorarse los documentos de la Santa Sede, referidos a las familias, en particular Familiaris Consortio y la Carta de los Derechos de la Familia, dados bajo el Pontificado de Juan Pablo II, y en donde en forma expresa se aboga por fundar familia vía el matrimonio, en este caso el religioso y civil, y la afirmación de que no se puede poner a la par del matrimonio al concubinato.

El derecho a heredarse entre concubinos ya existe en legislaciones como Bolivia, Ecuador, y en Centroamérica, México, El Salvador, Panamá, entre otros, por ello no debe llamar la atención la promulgación de esta ley, que viene a modificar sustantivamente la legislación sucesoria, en particular las instituciones de la sucesión intestada, y la legítima. 


\section{LA UNIÓN DE HECHO Y EL} Concubinato

La Constitución de 1979, que fue la primera que la recogió, describe la unión de hecho entre un hombre y una mujer, que viven como casados sin estarlo, y compartiendo los deberes y derechos propios del matrimonio; la Constitución de 1993, igualmente la denomina unión de hecho, y no la califica como concubinato.

La unión de hecho vendría a ser el género, pues puede haber uniones de hecho propias o regulares, en donde se cumplen las exigencias legales para serlo y obtener los beneficios que la ley les depara, pero igualmente coexisten con ellas las uniones de hecho impropias, en donde no se satisfacen las exigencias legales, y por ende no les alcanza beneficio alguno. Según nuestra Constitución, la unión de hecho implica, vida en común, cohabitación entre un hombre y una mujer, asumiendo las responsabilidades propias del matrimonio, y en donde las características de la comunidad de vida, permanencia, estabilidad, singularidad, notoriedad se dan; ahora bien, en doctrina a esta unión de hecho se le denomina concubinato, término éste que deriva de concubena, que etimológicamente significa dormir juntos. El concubinato que reúne todas las características que exige la Constitución en su artículo 4 y el Código Civil en su artículo 326, gozan de los beneficios que otorga la ley, y que se circunscribían a la equiparidad de la sociedad de bienes que se genera en el concubinato y el régimen de sociedad de gananciales, y hoy con la ley 30007, también el derecho a heredarse entre sí.

GANANCIALES Y HERENCIA, $Y$

El artículo 730 del Código Civil establece con meridiana claridad la distinción entre gananciales y cuota hereditaria, y lo hace en función del precedente que fue el Código Civil de 1936 que confundió ambos derechos, señalando que si los gananciales superaban la cuota hereditaria del cónyuge, entonces perdía esta cuota y se quedaba con los gananciales. Hoy la confusión ha sido superada con el artículo 730 , norma que igualmente debe ser aplicada en el caso de los concubinos.

Los gananciales aparecen como el resultado del trabajo de los consortes dentro del matrimonio, culminado éste, si existen ganancias, éstas deben ser repartidas en partes iguales, pues son ellos los que han generado estas ganancias llamadas gananciales, por otro lado, la cuota hereditaria, es un derecho que nace con el matrimonio, y hoy con la unión de hecho, como un reconocimiento a esta familia fundada en el matrimonio o en la unión de hecho, a la par que se reconoce el derecho hereditario de los hijos respecto de sus padres y viceversa, también se reconoce el derecho hereditario recíproco entre los cónyuges, o si fuera el caso, entre los concubinos. Por lo tanto se trata de dos derechos que tienen fuertes diferentes $y$ no admiten semejanza, y por ello ha hecho bien, el Código Civil al consignar una norma como el artículo 730 teniendo en cuenta el precedente legal de 1936.
Aún cuando resulte reiterativo, el artículo 730 igualmente es de aplicación a las uniones de hecho, en el que uno de ellos ha fallecido y en consecuencia al sobreviviente de la unión de hecho le corresponde no sólo gananciales sino también cuota hereditaria.

\section{ANÁLISIS DE LAS NORMAS CONTENIDAS EN LA LEY 30007, $Y$ QUE TERMINAN MODIFICANDO INSTITUCIONES COMO LA SUCESIÓN LEGAL, Y LA LEGÍTIMA}

\section{¿CuÁNDO ESTAMOS ANTE UNA UNIÓN DE HECHO QUE GENERE HERENCIA?}

Tal como lo hemos mencionado, esta unión de hecho tiene que ser una relación heterosexual, que viven como casados sin estarlo. Vivir como casados implica una vida en común compartiendo techo, lecho y mesa, comunidad de vida permanente, continua e ininterrumpida, adicionándose a ello, singularidad, esto es, exclusiva y excluyente entre los convivientes, pública y notoria, no a ocultas, sino a vista de todos. Dentro de esta comunidad de vida se dan los deberes propios del matrimonio, es decir surgen los deberes de cohabitación, fidelidad y asistencia.

A todas estas características debe sumársele una comunidad de vida con permanencia de dos o más años, y que no exista impedimento matrimonial entre los convivientes, esto es, si ellos decidieran casarse, no habría problema alguno en regularizar legalmente su situación. Estas características son las que contiene el artículo 326 del Código Civil, artículo que termina siendo modificado por la ley bajo 
comento, precisamente para aludir al derecho de herencia entre los integrantes de esta unión de hecho.

Tal como lo hemos mencionado, el código no utiliza el término concubinato, sin embargo no cabe duda que se está refiriendo a esta institución, y más propiamente al concubinato llamado regular o en estricto sentido (strictu sensu). En legislaciones extranjeras a esta unión de hecho se le denomina matrimonio de hecho, matrimonio no formalizado, convivencia, concubinato. Queda claro que la ley comentada no alcanza a las uniones de hecho impropia, irregulares o como llama la doctrina, concubinato lato, en tanto que estas uniones de hecho o existe impedimento matrimonial entre ellos, o la vida en común no alcanzó los dos años de vida como mínimo, o la convivencia no ha sido permanente, continua. A estas uniones de hecho, el artículo 326 del Código Civil le depara como única protección, la acción de enriquecimiento indebido cuando uno de ellos se ha enriquecido a costa del compañero durante la vigencia de la vida en común, en ese supuesto el concubino agraviado, puede demandar solicitando una indemnización.

Vigente La UNIÓN DE HECHO AL MOMENTO DEL FALLECIMIENTO DE CUALQUIERA DE SUS MIEMBROS

Haciendo un símil con el matrimonio en cuanto a los derechos hereditarios, diremos que para que proceda la sucesión entre los cónyuges es necesario que cuando se abre la sucesión, momento preciso de la muerte de uno de ellos, debe estar vigente el matrimonio, institución ésta que precisamente termina en ese acto por el deceso; ahora bien, si se trata de un matrimonio vigente, pero que por diversos motivos la pareja no vive juntos, ello resulta irrelevante, pues aún así el sobreviviente termina heredando a su consorte fallecido, tan es así, que nuestro Código Civil en su artículo 827, a propósito del matrimonio putativo, sólo concede herencia a la cónyuge putativa, si es que la primera cónyuge no sobrevive al causante, pero si le sobrevive, será ella la que resulta siendo la sucesora. Este trato legal, aparentemente no es aplicable al caso de la unión de hecho, pues la exigencia legal está dada en cuanto a que el derecho sucesorio sólo se va a dar, cuando al fallecer el concubino, su compañera estuvo viviendo con él, ergo, si no es así, y pese a haber estado conviviendo por mucho tiempo y satisfaciendo las exigencias legales del 326, no podría heredar. Este trato legal nos parece que puede llevar a serias injusticias, pues pueden darse casos, de parejas concubinas con reconocimiento o inscripción, pero que sin culpa del concubino sobreviviente, no se encontraban viviendo juntos cuando ocurre el deceso, en esa situación no podría heredar, si aplicamos el texto frío de la norma; sobre el particular, creemos que la interpretación de la norma debe ser extensiva para comprender estos casos.

Creemos que lo que busca la norma es proteger a estas parejas concubinarias, y la protección pasa por reconocerles derecho sucesorio, en tanto que han probado esta unión de hecho, independientemente de que al ocurrir el deceso del causante, estén viviendo juntos o no, salvo el caso de comprobado abandono, supuesto en el cual, los interesados tienen el derecho de acudir a la vía judicial para impugnar el reconocimiento de esa unión de hecho, y no sólo por el abandono sino por cualquier otra causal de indignidad o desheredación que aparte al posible sucesor de la herencia.

\section{UNIONES DE HECHO INSCRITAS EN EL REGISTRO PERSONAL O RECONOCIDAS POR LA VÍA JUDICIAL}

Se trata de una exigencia legal para gozar del derecho de herencia, y busca identificar a las uniones de hecho que hayan cumplido con los requerimientos sustantivos para ser considerados como tales, es decir la comunidad de vida de dos o más años y la no existencia de impedimento matrimonial entre los concubinos; ahora bien, al ocurrir el deceso del concubino o concubina, el sobreviviente debe tener inscrita en el registro personal la unión de hecho, o sentencia judicial que haya reconocido esta unión de hecho.

En cuanto a la inscripción en el registro personal, la ley 26662 modificada por la ley 29560, de competencia notarial, establece el procedimiento para obtener esta inscripción registral, el mismo que se resume en lo siguiente: solicitud de ambos concubinos pidiendo que se reconozca e inscriba en el registro personal su unión de hecho, acompañando los documentos pertinentes que acrediten tal unión y dos testigos que dan fe de ello; como es de observar, el petitorio dirigido al notario im- 
plica que existe consenso entre los concubinos para el reconocimiento de esa unión de hecho, así mismo inferimos que no es posible tal reconocimiento en esta vía notarial, cuando se solicita unilateralmente. El Notario manda publicar esta solicitud y vencido el término de la publicación (15 días), y al no haber oposición, el Notario levanta acta con el reconocimiento de la unión de hecho y pasa partes al registro personal para su inscripción.

En cuanto al reconocimiento judicial, ello implica un conflicto de intereses, pues estamos ante una unión de hecho, admitida por uno y negada por el otro, y por ello se acude al poder judicial para que resuelva ese conflicto de intereses. Actuadas las pruebas pertinentes, si el juez considera probada la existencia de esta unión de hecho, las reconoce como tal, y la resolución que quede con carácter de consentida, se inscribirá igualmente en el registro personal. Sin embargo sin existencia de conflicto, también se puede acudir a la vía judicial para el reconocimiento de la unión de hecho, cuando habiendo fallecido uno de ellos, no se había inscrito la citada unión.

En este orden de ideas, contempla la ley la situación de que al fallecer el causante, no exista ni inscripción registral por la vía notarial, ni por la vía judicial, en esa circunstancia la ley 30007 señala expresamente lo siguiente " ...el integrante sobreviviente puede solicitar el reconocimiento judicial de la unión de hecho, si antes del fallecimiento del causante, no se hubiera realizado la inscripción registral".
MODIFICACIONES DE LA LEY 30007, RESPECTO DE LOS ARTÍCULOS DE SUCESIONES NÚMEROS $725,727,730,731,732$, $822,823,824$ Y 825 DEL CÓDIGO CIVIL

Tal como ya lo hemos mencionado las modificaciones que introduce la ley bajo comento, están referidas a la sucesión entre concubinos, en el ámbito de la sucesión legal e igualmente en la institución de la legítima, e indirectamente también tiene que ver con la sucesión testamentaria, aún cuando la ley no lo mencione, y ello es así, en función de que al convertirse en legitimario al concubino, es decir heredero forzoso ( según nuestra ley), es un sucesor que de todas maneras hereda, salvo causales de desheredación, y en esa medida, la persona que desea testar, y tenga una compañera o compañero según el caso, deberá considerar a ella, o a él, según se trate, y no hacerlo, implicaría entrar al terreno de la preterición, que significa, no considerar un heredero forzoso dentro del testamento, dando lugar al derecho del preterido a acciones legales para que se reconozca su situación.

\section{Artículo 725}

El numeral citado alude a la cuota de libre disposición; en efecto, dentro de la institución de la legítima, porción de la herencia reservada a los herederos forzosos, existe una cuota que es de libre disposición del testador, en un caso es un tercio, cuando los herederos forzosos son descendientes o cónyuge o ambos, y ahora agregamos concubino, y la mitad del patrimonio hereditario cuando los herederos forzosos son los as- cendientes del causante. En el caso que estamos comentando, se ha adicionado a los herederos forzosos, al concubino poniéndolo a la par del cónyuge, en consecuencia el artículo 725, debe leerse ahora, considerando como herederos forzosos no sólo a los descendientes, ascendientes y cónyuge, sino también al concubino, o concubina sobreviviente, por lo tanto si el testador al momento de testar, tiene compañera concubina, no podrá disponer de todo su patrimonio, sino que deberá considerarla obligatoriamente como heredera con dos tercios del patrimonio a esta compañera o compañero, pudiendo sólo disponer libremente del tercio del patrimonio, y de no hacerlo, es decir sino respeta la norma, y dispone de su cuota de libre disposición excediendo el porcentaje establecido por la ley, el exceso será inoficioso, pues está afectando la legítima del concubino.

\section{Artículo 727}

La norma está referida a la libre disposición de todo el patrimonio hereditario al no contar con herederos forzosos; en efecto el artículo citado alude a que si el testador no tiene descendientes, ascendientes ni cónyuge, puede disponer de todo su patrimonio como mejor le parezca, en este caso, la ley no lo limita, sino todo lo contrario, lo faculta para que en uso de una libertad irrestricta de disposición de su patrimonio por testamento, pueda destinar el mismo a personas naturales o jurídicas, instituir herederos voluntarios, 0 dejar los bienes y derechos que integran su patrimonio en legados; ahora bien, la modificación de la norma a propósito de la 
ley 30007, incluye al integrante sobreviviente de la unión de hecho como un heredero forzoso más, y con una cuota de las dos terceras partes del patrimonio del causante, en consecuencia el artículo 727 del Código Civil debe interpretarse en el sentido de que si el causante no tiene descendientes, ascendientes, cónyuge o concubino, puede disponer libremente de todo su patrimonio hereditario. Repárese que la ley protege a los herederos forzosos, como sucesores naturales del causante y que han formado parte integrante de la vida familiar del causante, y por este vínculo cercano y directo con el mismo, es que la ley les reserva una parte del patrimonio del causante, obligándolo a éste, a no disponer de ese patrimonio bajo sanción de no surtir efectos esa disposición, y ahora tenemos al sobreviviente de la unión de hecho como otro legitimario más a quien de todas maneras debe considerarse, ya que a los descendientes, ascendientes y cónyuge se ha sumado el concubino o concubina sobreviviente y sólo cuando ninguno de los herederos forzosos no concurran a la sucesión, entonces el testador puede disponer libremente de su patrimonio.

\section{Artí́culo 730}

La norma está referida a la distinción que separa a dos derechos que fácilmente se confunden al ocurrir la muerte de una persona casada bajo el régimen de sociedad de gananciales; nos estamos refiriendo precisamente a los gananciales y a la herencia, y así el numeral citado señala que la legítima del cónyuge es independiente del derecho que le corresponde por concep- to de gananciales proveniente de la liquidación de la sociedad de bienes del matrimonio. Sobre el particular repárese que la norma está ubicada en la legítima, y más precisamente referida al legitimario cónyuge, y se pronuncia sobre la diferencia existente (tratándose de un régimen de sociedad de gananciales), entre gananciales y legítima, o cuota hereditaria del cónyuge. El presente artículo tiene sentido, tal como ya lo hemos reseñado, en vista del precedente legal del Código Civil de 1936 que confundió gananciales con cuota hereditaria, estableciendo que si los gananciales llegaban o superaban la cuota hereditaria, entonces perdía ésta y se quedaba sólo con los gananciales. Como vemos, en el presente se hace el distingo, en razón de que se trata de dos derechos diferentes por su procedencia y su naturaleza jurídica; en efecto, los gananciales que aluden a ganancias obtenidas a lo largo de la vida matrimonial, y al concluir ésta, entonces se entrega a cada consorte el $50 \%$ de esos gananciales, en tanto que son ellos los que lo generaron, y si fuera el caso de que la sociedad ha terminado por muerte de uno de los cónyuges, entonces el sobreviviente recibe sus gananciales, y lo que le hubiera correspondido al causante, constituye el patrimonio hereditario que está dejando. Por otro lado, la legítima, o cuota hereditaria del heredero forzoso cónyuge, es un derecho reconocido por ley a propósito del matrimonio que es fuente generadora de derechos y deberes, y así como el parentesco crea derechos y también deberes, y dentro de esos derechos se encuentra la herencia, el matrimonio también es fuente generadora, y por ello el cónyuge tiene derecho a heredar a su consorte y viceversa, en consecuencia y de conformidad con lo dispuesto en el artículo 730 del Código Civil, acaecida la muerte de un cónyuge, primero se liquida la sociedad de gananciales, y se entrega al sobreviviente el $50 \%$ de esos gananciales, y sobre los otro $50 \%$, que constituyen el patrimonio hereditario, es llamado a la herencia del cónyuge fallecido, el sobreviviente; si no hubiera descendientes, ni ascendientes, el cónyuge se queda con toda la herencia, y si hubiera descendientes, el cónyuge supérstite tiene una cuota hereditaria igual a la de un hijo del causante. Así expuesto el tema, y a propósito de la ley 30007 , al sobreviviente de la unión de hecho declarada e inscrita como tal en el registro personal, también le corresponde en aplicación del artículo 326 del código civil, el $50 \%$ de los gananciales de la sociedad de bienes generada a lo largo de la vida concubinaria, y ahora con la ley 30007, también le corresponde heredar al concubino causante, solo o en concurrencia con ascendientes, o descendientes del causante. En consecuencia, el artículo 730 del Código Civil debe leerse no sólo refiriéndose a la figura del cónyuge, sino también a la concubina o concubino.

\section{Artículo 731}

El numeral citado alude al derecho del cónyuge supérstite para seguir viviendo en el inmueble que fue el hogar conyugal, constituyendo un derecho de habitación vitalicio y gratuito, derecho que se da cuando al concurrir con otros sucesores, sus cuotas de gananciales y cuo- 
ta hereditaria, no alcanzan para adjudicarse el inmueble que fue el hogar conyugal. Hasta antes de la ley 30007 que estamos comentando, sólo podían acceder a este derecho los casados, y no sólo cuando habían estado bajo el régimen de sociedad de gananciales, sino también cuando su matrimonio estuvo sometido al régimen de separación de patrimonios, pues bien, ahora este derecho también puede ser invocado por el sobreviviente de una unión de hecho, sea mujer u hombre, si al fallecer el causante, el sobreviviente concurre a la sucesión con otros sucesores del causante. Recordemos que el artículo 326 en aplicación del artículo 5to de la Constitución ya le reconocía derechos sobre el patrimonio social generado en la unión de hecho, cuando esta unión había terminado, siendo uno de los supuestos la muerte de uno de los concubinos; en esa medida, si dentro del patrimonio social, sociedad de bienes llama el artículo 326 , se encuentra un inmueble, el cual fue destinado a la residencia de la pareja, entonces, sobre ese bien, recaerá el derecho de habitación vitalicio, si es que los supuestos del artículo 731 se dan, esto es, sus gananciales ( respecto del inmueble) y su cuota hereditaria ( hoy se lo concede la ley 30007) no alcanzan el valor de dicho inmueble para su adjudicación, en esa medida tiene la facultad de ejercer este derecho de habitación, esto es, seguir viviendo en el bien, con lo cual los otros sucesores no podrán partir, dividir el inmueble sujeto a derecho de habitación, pues están recibiendo un bien, conjuntamente con la sobreviviente, pero con la carga que impone el derecho de habitación, no partir, no dividir, no vender el inmueble hasta que se extinga el derecho de habitación, es decir ocurra la muerte de la sobreviviente, renuncie, se case o ingrese a otro concubinato, supuestos, todos en los que los otros sucesores, ya quedan libres de disponer del bien.

Tal como venimos haciendo con los otros artículos modificados por la ley, el artículo 731, debemos leerlo, en el sentido de que el derecho de habitación del cónyuge supérstite es del cónyuge viudo, o de la concubina viuda al concurrir con los otros sucesores del causante.

\section{Artículo 732}

Este artículo sigue desarrollando el derecho de habitación del cónyuge supérstite y hoy también derecho del sobreviviente de la unión de hecho; ahora bien, la norma faculta, con autorización judicial, a arrendar el inmueble sobre el cual recae el derecho de habitación, cuando el beneficiario se encuentre en precariedad económica y no pueda solventar los gastos derivados del inmueble. La norma también establece los supuestos en los cuales termina el derecho de habitación, y señala que son el fallecimiento del que viene ejerciendo el derecho, renuncia al derecho, contraer nuevo matrimonio o ingresar a un concubinato, y en lo que se refiere al sobreviviente de la unión de hecho, el derecho de habitación terminará cuando se produzca su deceso, renuncia al derecho, contraer matrimonio o ingresar a un nuevo concubinato. Sobre estos supuestos, no merece mayor comentario los referidos a la muerte y a la renuncia, mas sí los que atañe a la celebración del matrimonio, en tanto que el legislador supone que al celebrarse el matrimonio, cesa o desaparece la necesidad de habitabilidad que estuvo presente, cuando concluyó el matrimonio por muerte del causante, y en la misma línea, podemos afirmar que igual sucede con el sobreviviente de la unión de hecho, cuando celebra matrimonio o ingresa a un nuevo concubinato; sobre el particular y el real o supuesto cese de necesidad de habitación, termina siendo discutible, sin embargo lo cierto del caso, es que el derecho de habitación, es una carga a los otros sucesores que concurren con el sobreviviente, quienes están a la espera de la culminación del derecho para poder hacer efectivos los suyos sobre el patrimonio hereditario, $y$, no considerar a los supuestos comentados como cese del derecho, tornaría el derecho de habitación como un derecho absoluto e indeterminado, con grave perjuicio para los otros sucesores, y entendemos que ello no es lo que busca el legislador, ni está en el espíritu de la norma.

\section{Artículo 822}

Esta norma se ubica dentro de la sucesión legal, lo que supone que es la ley quien determina quiénes son los sucesores del causante y establece un orden de herederos legales que están consignados en el artículo 816. La norma se ubica en el título del cónyuge sucesor legal concurriendo con los descendientes del causante, y en esa medida, se establece que el cónyuge hereda una cuota igual a la de un hijo del causante. Para los efectos de la sucesión legal, debemos contemplar la presencia 
del cónyuge del causante como un heredero que para todos los efectos sucesorios hereda una cuota igual a la de un hijo, no interesando si son sus hijos o no lo son. La ley 30007 bajo comento, al poner a la par del cónyuge del causante al sobreviviente de la unión de hecho implica que es un heredero legal de tercer orden, pero que hereda con los del primer y segundo orden, y cuando concurre con descendientes, su cuota es igual a la de un hijo.

\section{ARTículo 823}

Siempre dentro de la sucesión del cónyuge, se establece en la norma citada, la opción del cónyuge supérstite cuando concurre con descendientes del causante, la de continuar siendo heredera y por lo tanto realizar la división y partición de los bienes y derechos de la herencia, o la de elegir en calidad de usufructo la tercera parte de la herencia, con lo cual deja de ser heredera pero gana el derecho a ser usufructuaria del tercio de ese patrimonio hereditario, afectando a los otros sucesores, que se quedan con la propiedad de todo el patrimonio, pero no podrán partir o dividir hasta que se extinga el derecho de usufructo, en pocas palabras tienen la nuda propiedad sobre el todo. Esta norma en aplicación de la ley 30007, debe recaer también al sobreviviente de la unión de hecho cuando concurre con descendientes del causante, pudiendo elegir este derecho de usufructo. La norma está pensada, siempre privilegiando al cónyuge del causante y hoy también a la concubina viuda, favoreciendo al supérstite cuando la concurrencia con descendientes es numerosa, en esa situación si se decidiera continuar como heredera, su cuota llega a atomizarse, en tanto que, como ya quedó claro, su cuota es la de un descendiente del causante. Por ejemplo, si la concurrencia se da con doce hijos del causante, entonces al cónyuge le corresponderá una 13ava parte de la herencia, en ese supuesto sería más provechoso gozar en calidad de usufructuario de la tercera parte del patrimonio hereditario.

\section{Artículo 824}

El presente artículo está referido a la concurrencia del cónyuge con ascendientes del causante, en esa circunstancia la cuota del cónyuge es igual a uno de los ascendientes. Se debe destacar en esta norma el privilegio del cónyuge, pues termina siendo un heredero de tres órdenes, en tanto que concurre con los descendientes del causante, con los ascendientes, y si no hubiera ninguno de ellos, todo el patrimonio hereditario le corresponde, lo que significa que a diferencia del Código Civil de 1936 el cónyuge ha desplazado a los hermanos del causante al cuarto orden hereditario, mientras que con el derogado código, concurría con los hermanos del causante; ahora bien, la cuota del cónyuge es igual al que corresponde al ascendiente, sin hacer distingos respecto de qué ascendientes son los que concurren con el cónyuge, pues puede tratarse de los padres del causante, en esa medida la herencia termina dividiéndose en tres partes, y si fuera el caso de que no siendo hábiles los padres del causante, pero lo son cuatro abuelos del causante, entonces la herencia se dividirá en cinco partes, es decir a ma- yor número de ascendientes, la cuota de la cónyuge se minimiza pues tendrá que compartir en partes iguales, la herencia con todos los ascendientes que concurran, norma que dista mucho de alcanzar un trato justo, pues el cónyuge resulta siendo el perjudicado, sobre todo en concurrencia con ascendientes lejanos del causante, en tanto que la norma se justifica con la concurrencia de los padres del causante ( parientes en línea recta ascendiente de primer grado) , pero no lo es cuando concurre con abuelos del causante ( parientes en línea recta ascendiente de segundo grado). En cuanto a la presencia del sobreviviente de la unión de hecho, la norma que estamos comentando tiene igual aplicación, por lo tanto el artículo 824 debe leerse en el sentido de concurrencia del sobreviviente de la unión de hecho con ascendientes del causante, en ese caso la cuota del concubino supérstite es igual a la de los ascendientes.

\section{Artículo 825}

Este numeral ubicado en sucesión legal, parte del supuesto de que al abrirse la sucesión del causante, no existan descendientes ni ascendientes hábiles del causante pero sí cónyuge, en esa circunstancia todo el patrimonio hereditario corresponde al cónyuge sobreviviente; ahora bien, habiéndose establecido el derecho hereditario del sobreviviente de una unión de hecho que cumpla con las exigencias del artículo 326, a las que debe adicionarse la inscripción registral de esa unión o declaración judicial de la referida unión de hecho, en esa circunstancia el artículo 825 termina 
concediendo derecho exclusivo de la herencia a favor del sobreviviente de esa unión de hecho, en consecuencia el concubino sobreviviente excluye a todos los parientes del cuarto, quinto y sexto grado en línea colateral del causante.

\section{Artículo 724}

Califica a los herederos forzosos o legitimarios, quienes de todas maneras concurren a la sucesión del causante si no hubiera causales de desheredación, respetándose la exclusión de los ascendientes cuando existan descendientes. Señala el numeral que son herederos forzosos, los descendientes, ascendientes y cónyuge del causante, ahora bien con la ley 30007 , debemos agregar a estos llamados herederos forzosos, legitimarios o herederos necesarios, también al sobreviviente de una unión de hecho que cumpla con las exigencias legales para gozar de los beneficios que la ley le depara, como es el derecho a heredarse entre sí.

Siguiendo el concepto de la institución de la legítima, que opera tanto en sucesión legal como en sede testamentaria, diremos que si el causante tiene concubino o concubina, deberá tenerlo en cuenta al momento de disponer libremente de su patrimonio, pues la ley le ha reservado al concubino, como lo hace con todos los herederos forzosos, una participación en el patrimonio del causante, y que en este caso es de dos tercios de ese patrimonio, que reiteramos, la ley los reserva a los legitimarios, descendientes, y cónyuge, y ahora concubino, y si no respeta la presencia de este heredero forzoso, la dispo- sición realizada por el causante corre el riesgo de ser inoficiosa, tal como aparece del artículo 1629 del Código Civil, artículo que termina complementando las disposiciones de la legítima, disposiciones legales que como sabemos tienen la calidad de normas de orden público.

\section{Artículo 816}

El presente numeral alude a los seis órdenes de herederos legales que reconoce nuestro Código Civil, (orden de prelación) y en donde aparece el cónyuge del causante, ocupando teóricamente el tercer orden, pero en la práctica es un heredero de tres órdenes, ya que hereda al causante concurriendo con los descendientes de éste, hereda al causante concurriendo con los ascendientes de éste, y si no hubiera descendientes y ascendientes hábiles, el cónyuge termina llevándose sólo el patrimonio hereditario; ahora bien, con la ley 30007 , se incluye igualmente en este orden, y a la par del cónyuge del causante, al sobreviviente de la unión de hecho, en esa medida, diremos que el vigente orden hereditario, es el siguiente: primero, los hijos y demás descendientes del causante; de segundo orden y en defecto del primero, los ascendientes del causante; del tercer orden, el cónyuge o en su caso el sobreviviente de la unión de hecho; de cuarto orden los parientes colaterales del segundo grado del causante; de quinto orden, los parientes colaterales del tercer grado y de sexto orden los parientes colaterales de cuarto grado del causante, haciéndose la salvedad de que el cónyuge del causante, o en su caso el sobreviviente de la unión de hecho, hereda al cau- sante en concurrencia con el primero y segundo orden.

\section{Artículo 2030}

Referido al Registro Personal, habiéndose establecido un supuesto más de inscripción en el registro, y es el que comprende a las uniones de hecho inscritas en vía notarial o reconocidas por vía judicial, para lo cual, el notario, o en su caso el juez, cursarán los partes respectivos a este registro personal para su inscripción.

\section{MODIFICACIONES DE LOS ARTíCULOS 425 Y 831 DEL CÓDIGO PROCESAL CIVIL}

En efecto, la ley que comentamos modifica el artículo 425 referido a los anexos que deben adjuntarse con la demanda, y en el supuesto de una unión de hecho, deberá anexarse la prueba de la calidad de heredero cónyuge o en su caso sobreviviente de la unión de hecho, y el 831 , sobre el proceso de sucesión intestada, acompañándose a la solicitud, en su caso, la constancia de inscripción de la unión de hecho en el registro personal.

\section{MODIFICACIONES DE LOS ARTíCULOS 35, 38 E INCISO 4 DEL ARTíCULO 39 DE LA LEY 26662}

La citada ley regula la competencia de los notarios públicos, y el artículo 35 está referido a la solicitud de comprobación del testamento, la misma que ahora puede ser solicitada también por el integrante sobreviviente de la unión de hecho reconocida conforme a ley; el artículo 38 alude a la sucesión intestada, y que ahora también puede ser solicitada por el so- 
breviviente de la unión de hecho reconocida conforme a ley ante el Notario del lugar del último domicilio del causante, y el inciso cuarto del artículo que gira igualmente sobre la petición de una sucesión intestada, alude a los documentos que deben aparejarse con dicha solicitud, habiéndose incluido, de ser el caso, la inscripción en el registro personal de la declaración de unión de hecho, o la copia certificada de la sentencia judicial firme que reconozca esta unión de hecho.

\section{Consideraciones finales}

Diversos códigos del continente habían concedido el derecho hereditario a los concubinos, y el Perú, era uno de los países faltantes en el reconocimiento de la herencia entre los integrantes de una unión de hecho; ahora bien, ello se da en un contexto en el que el Tribunal Constitucional, órgano supremo intérprete de la Constitución venía emitiendo resoluciones otorgando derechos diversos a los concubinos, en tanto que forman familia, y merecen por lo tanto la protección del Estado, tal como lo reconoce el artículo cuarto de nuestra Carta Magna, derechos como reconocer las diferentes formas familiares, ( familias monoparenta- les, familias ensambladas, familias concubinarias), derechos pensionarios a favor del sobreviviente de la unión de hecho, cuando el compañero o compañera ha fallecido, derechos a no ser discriminados los hijos afines con los biológicos cuando todos ellos viven formando una nueva identidad familiar ( familia ensamblada). Por otro lado, el número cada vez más creciente de las uniones de hecho reflejada en los diversos censos ocurridos en el Perú, y que no reflejan la verdadera dimensión de estas uniones de hecho, el cambio que viene operando en nuestra sociedad en la que se ha dejado de estigmatizar a estas uniones de hecho e incluso a los hijos habidos de estas parejas, en tanto que ahora son vistas como una situación parecida sino igual a las uniones matrimoniales, todo ello ha llevado a que a través de esta ley se conceda este derecho trascendente e importante de la herencia entre concubinos, en la medida en que se cumplan las exigencias legales.

Sin embargo, y esto no debe verse como una crítica, sino como un hecho comprobable, es que este derecho hereditario que viene a sumarse al que ya tenían las uniones de hecho, es decir la equiparidad legal de la sociedad de bienes que se genera en una unión de hecho con la sociedad de gananciales que se da dentro del matrimonio, parece conducir a una igualdad en todo orden de cosas entre el concubinato regular, y el matrimonio, pues si bien es cierto ambas son formas de fundar familia, también lo es que hoy poco menos que en el campo patrimonial, el concubinato y el matrimonio gozan de derechos similares, faltando sólo reconocerle derecho de alimentos entre los concubinos que siguen siéndolo, y que el patrimonio familiar pueda ser constituido no sólo por los cónyuges, sino también por los concubinos, y si ello se da entonces si habría un trato igualitario al matrimonio, y en ese supuesto nos preguntamos cómo queda el deber del Estado de promover el matrimonio tal como lo consagra el artículo 4 de la Constitución?, no representaría una forma de desmotivar o desincentivar a que las personas contraigan matrimonio, en razón de que sin celebrarlo y formando uniones de hecho van a tener los mismos derechos que los casados?. Son inquietudes que le suscitan al autor de este artículo, y de seguro a otro número importante de personas que siempre han tenido al matrimonio como una fuente natural de fundar familia. 